\title{
Association of peroxisome proliferator- activated receptor-delta polymorphisms with sugar metabolism indices and tumor necrosis factor alpha level
}

\author{
X.J. Yu' ${ }^{1}$, B.L. Su ${ }^{2}$, X.M. Wang', H.J. Feng ${ }^{1}$ and C.J. Jin ${ }^{1}$ \\ ${ }^{1}$ Affiliated Zhongshan Hospital of Dalian University, Dalian, China \\ ${ }^{2}$ The Second Hospital of Dalian Medical University, Dalian, China \\ Corresponding author: B.L. Su \\ E-mail: yxj_y@sina.com
}

Genet. Mol. Res. 13 (3): 5088-5093 (2014)

Received May 14, 2013

Accepted November 27, 2013

Published July 7, 2014

DOI http://dx.doi.org/10.4238/2014.July.7.1

\begin{abstract}
This study aims to investigate the association of peroxisome proliferator-activated receptor (PPAR) delta $-87 \mathrm{~T} / \mathrm{C}$ polymorphism with several sugar metabolism indices and tumor necrosis factor $\alpha$ (TNF $\alpha$ ) level. The body mass index (BMI), waist size, and levels of fasting plasma glucose, serum lipid, fasting insulin, TNF $\alpha$, and PPAR delta $-87 \mathrm{~T} / \mathrm{C}$ of 286 patients with type 2 diabetes mellitus $\left(\mathrm{T}_{2} \mathrm{DM}\right)$ and 158 subjects with normal fasting glucose (NFG) were measured in a Dalian population. The distribution of genotypic frequencies between $\mathrm{T}_{2} \mathrm{DM}$ and NFG were not significantly different $\left(\chi^{2}=0.012, P=0.994\right)$. BMI, fasting blood glucose $(\mathrm{FBG})$, homeostasis model assessment-estimated insulin resistance (HOMAIR), triglyceride, and TNF $\alpha$ levels were significantly different among different $\mathrm{T}_{2} \mathrm{DM}$ genotypes. HOMA-IR and FBG were significantly different among different NFG genotypes. The PPAR delta $-87 \mathrm{~T} / \mathrm{C}$ polymorphism is known to be closely related with glucose levels and lipid metabolism. A close relationship was also found between
\end{abstract}


HOMA-IR and TNF $\alpha$ levels and HOMA-IR and FBG in $\mathrm{T}_{2} \mathrm{DM}$ and NFG, respectively.

Key words: Peroxisome proliferator-activated receptor delta; Type 2 diabetes mellitus; Polymorphism

\section{INTRODUCTION}

Peroxisome proliferator-activated receptor (PPAR) delta, a member of the PPAR family, is ubiquitously expressed (Skogsberg et al., 2000). It has been reported to be involved in the regulation of genes that participate in lipid and lipoprotein metabolism (Leibowitz et al., 2000; Oliver Jr. et al., 2001), as well as in the oxidation of adipose tissue and muscle fatty acids (Tanaka et al., 2003; Holst et al., 2003; Dressel et al., 2003). The role of PPAR-delta in the response of cells to inflammation has also been documented (Michalik et al., 2001; Tan et al., 2001). Unlike PPAR- $\alpha$ and PPAR- $\gamma$, PPAR-delta has fatty acids as their natural ligands (Forman et al., 1997). A polymorphism in the 5'-untranslated region of the PPAR-delta gene has been identified as $-87 \mathrm{~T}>\mathrm{C}$ (also named $+294 \mathrm{~T}>\mathrm{C}$; Skogsberg et al., 2003a; Shin et al., 2004), which is also associated with the plasma lipid profile (Skogsberg et al., 2003a, b). Transient transfection assays revealed that the $-87 \mathrm{C}$ allele has higher transcription activity, indicating that PPAR-delta has a high activity (Skogsberg et al., 2003b). Tumor necrosis factor $\alpha$ (TNF $\alpha$ ), an inflammation factor released by fat cells and macrophages, plays a very important role in conferring resistance to diabetes and insulin among obese individuals (Zinman et al., 1999; Kern et al., 2001). Experiments involving animals have shown that PPAR-delta can decrease the signal transduction of TNF $\alpha$ and adjust lipid metabolism. Therefore, the present study aimed to investigates the association of PPAR-delta -87T/C polymorphism with several sugar metabolism indices and TNF $\alpha$ level.

\section{MATERIALS AND METHODS}

\section{Materials}

The study population was divided into 2 groups. A total of 286 patients were in Group $\mathrm{T}_{2} \mathrm{DM}$ (type 2 diabetes mellitus), which included 162 men and 124 women (median age, $63.48 \pm$ 10.56 years). The patients selection criteria were in accordance with the recommended by World Health Organization standard, 1999. All cases were in-patients at the Endocrinology Department of the Affiliated Zhongshan Hospital of Dalian University. A total of 158 patients were in Group NFG (normal fasting glucose), which included 88 men and 70 women (median age, $64.57 \pm$ 12.60 years). The fasting plasma glucose of the patients in Group NFG was under 5.6 mM. All patients were selected from the Health Examination Center of the Affiliated Zhongshan Hospital of Dalian University. This study was conducted in accordance with the Declaration of Helsinki. This study was conducted with the approval from the Ethics Committee of Zhongshan Hospital of Dalian University. Written informed consent was obtained from all participants.

\section{Methods}

The general information of patients, such as height, weight, body mass index (BMI), 
waist circumference, blood pressure, total cholesterol (TCh), triglyceride (TG), HDL-Ch, LDL-Ch, HbA1c, fasting plasma glucose, fasting plasma insulin, and plasma TNF $\alpha$ density, was collected. The insulin resistance index was calculated as follows: HOMA-IR = FPG x FINS/22.5. The TNF $\alpha$ density was measured using enzyme-linked immunosorbent assay (ELISA). The PPAR-delta $-87 \mathrm{~T} / \mathrm{C}$ polymorphism was analyzed by extracting the DNA using the Genome DNA Extra Kit (Takara Biotechnology, Co. Ltd. Dalian, China). The PPAR-delta $-87 \mathrm{~T} / \mathrm{C}$ mononucleotide polymorphism was detected using polymerase chain reaction-restriction fragment length polymorphism (PCR-RFLP). The sequences of the upstream and downstream primers were 5'-TGGGAAGGTGATAGGGCA-3' and 5'-CTGGTGAGTGGCAGAGCAGA-3', respectively. Both the primers were obtained from TakaRa Ltd. (Dalian, China).

The reaction conditions were as follows: fore-denaturation at $94^{\circ} \mathrm{C}$ for $5 \mathrm{~min} ; 35 \mathrm{cy}-$ cles of denaturation at $94^{\circ} \mathrm{C}$ for $45 \mathrm{~s}$, annealing at $58^{\circ} \mathrm{C}$ for $45 \mathrm{~s}$, and elongation at $72^{\circ} \mathrm{C}$ for 45 $\mathrm{s}$; and final elongation at $72^{\circ} \mathrm{C}$ for $5 \mathrm{~min}$. The amplified PCR product was cleaved using FokI at $37^{\circ} \mathrm{C}$ for $3.5 \mathrm{~h}$. The product was subsequently genotyped.

\section{Statistical analysis}

The genotype distribution was consistent with the Hardy-Weinberg equilibrium. Data were analyzed using SPSS 11.5. The chi-square analysis was used for data comparison.

\section{RESULTS}

The PCR product had a length of $602 \mathrm{bp}$. The TT homozygote created 3 fragments with lengths of 69,123 , and $410 \mathrm{bp}$. The CC homozygote created 2 fragments with lengths of 123 and $479 \mathrm{bp}$. The TC heterozygote created 4 fragments with lengths of 69, 123, 410, and 479 bp (Figure 1).

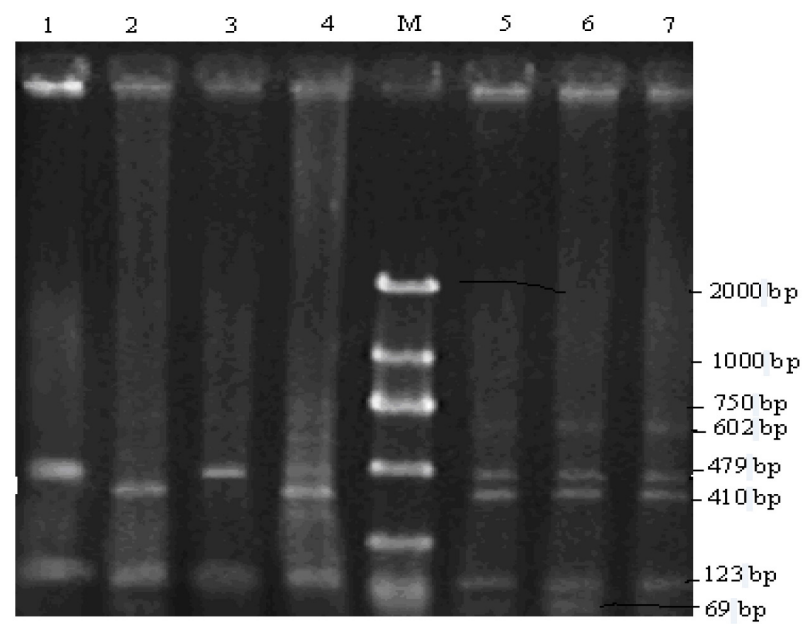

Figure 1. Agarose gel electrophoresis. Agarose gel electrophoresis showed the PCR product digested by Fok I: Lane $M=$ DNA Ladder Marker, genotypes of hole 1 and 3 were CC (479 and 123 bp), genotype of hole 2 was TT $(410,123$, and $69 \mathrm{bp})$, genotype of hole 4 to 7 were TC $(479,410,123$, and $69 \mathrm{bp})$. 
In Group $\mathrm{T}_{2} \mathrm{DM}$, the PPAR-delta genotypic frequencies of TT, TC, and CC were 47.4, 45.0, and 7.6\%, respectively, and the allele frequencies of $\mathrm{T}$ and $\mathrm{C}$ were 68.8 and $31.2 \%$, respectively. In Group NFG, the PPAR-delta genotypic frequencies of TT, TC, and CC were 47.2, 45.7, and 7.1\%, respectively, and the allele frequencies of $\mathrm{T}$ and $\mathrm{C}$ were 69.3 and $30.7 \%$, respectively. This suggested that there were no differences in the distribution of genotypic frequencies between Groups $\mathrm{T}_{2} \mathrm{DM}$ and NFG $(\mathrm{P}>0.05)$.

The comparison of different genotypes performed using clinical markers is shown in Table 1. Fasting plasma glucose and BMI were significantly different between the TT, TC, and $\mathrm{CC}$ genotypes in Group $\mathrm{T}_{2} \mathrm{DM}$. Triglyceride levels were also significantly different between the TC and CC genotypes. This result indicates that triglyceride is associated with fat metabolism in patients with type 2 diabetes. In addition, the insulin resistance index and TNF $\alpha$ level were significantly different between the TT and CC genotypes in Group $\mathrm{T}_{2} \mathrm{DM}$, which suggested that gene polymorphism, as well as chronic inflammatory factors, were related to insulin resistance in type 2 diabetes patients. Fasting plasma glucose and insulin resistance index were also significantly different between the genotypes in Group NFG. These data suggest that PPAR-delta polymorphisms have no correlations with BMI, TNF $\alpha$, and triglyceride in Group NFG (Table 1).

Table 1. Comparison of the clinical indicators in different genotypes of DM and NFG groups.

\begin{tabular}{lccccccc}
\hline Groups & The number of cases & Genotypes & Glu $(\mathrm{mM})$ & BMI $\left(\mathrm{kg} / \mathrm{m}^{2}\right)$ & HOMA-IR & TNF $\alpha(\mathrm{pg} / \mathrm{mL})$ & TG $(\mathrm{mM})$ \\
\hline \multirow{3}{*}{ DM } & \multirow{2}{*}{286} & TT & $9.05 \pm 3.31$ & $24.86 \pm 2.31$ & $0.44 \pm 0.29$ & $12.83 \pm 7.43$ & $2.11 \pm 1.74$ \\
& & TC & $8.08 \pm 3.17$ & $25.14 \pm 2.61$ & $0.32 \pm 0.28^{\star}$ & $11.14 \pm 4.83^{\star}$ & $1.75 \pm 0.93$ \\
& \multirow{2}{*}{158} & CC & $6.75 \pm 1.77^{* *}$ & $26.67 \pm 2.94^{*}$ & $0.31 \pm 0.28^{*}$ & $9.65 \pm 4.15^{*}$ & $2.72 \pm 2.68^{\sharp}$ \\
\multirow{2}{*}{ NFG } & TT & $5.01 \pm 0.35$ & $24.33 \pm 2.50$ & $0.23 \pm 0.13$ & $10.98 \pm 6.70$ & $1.41 \pm 0.78$ \\
& & TC & $4.81 \pm 0.40^{\star}$ & $24.75 \pm 2.80$ & $0.25 \pm 0.12$ & $11.18 \pm 7.52$ & $1.47 \pm 0.66$ \\
& & CC & $5.21 \pm 0.47^{*}$ & $24.95 \pm 4.00$ & $0.31 \pm 0.17^{*}$ & $12.07 \pm 8.75$ & $1.27 \pm 0.46$
\end{tabular}

Insulin resistance index is does not have a normal distribution, taking the natural logarithm of analysis of variance. *Significant differences between genotypes TT and CC $(\mathrm{P}<0.05)$; " significant differences between genotypes TC and $\mathrm{CC}(\mathrm{P}<0.05) ;{ }^{\mathbf{\Delta}}$ significant differences between genotypes TT and TC $(\mathrm{P}<0.05)$.

\section{DISCUSSION}

PPAR-delta, also called PPAR- $\beta$ or fatty acid-activated receptor, has 441 amino acid residues. Its coding gene is located in 6p 21.1-21.2 (Yoshikawa et al., 1996), which includes 11 exons. PPAR-delta is highly expressed in tissues involved in fat metabolism, such as small intestine, heart, muscles, and fat. Moreover, recent studies have shown that PPAR-delta is closely related with sugar and fat metabolism (Lee et al., 2003).

$\mathrm{TNF} \alpha$ is an inflammation factor secreted by fat cells and macrophages. It plays a very important role in insulin resistance and diabetes among obese individuals. Experiments involving animals have shown that PPAR- $\gamma$ can regulate lipid metabolism and decrease the signal transduction of TNF $\alpha$ to increase insulin sensitivity, thus improving fat metabolism.

Studies on PPAR-delta have recently attracted increasing attention. PPAR-delta has shown to play a very important role in controlling the fatty acid oxidation of muscle and fat tissues. Moreover, it is related to insulin sensitivity. A previous study revealed that the haplotype, composed of $-13454 \mathrm{G}>\mathrm{T},-87 \mathrm{~T}>\mathrm{C}, 2022+12 \mathrm{G}>\mathrm{A}, 2629 \mathrm{~T}>\mathrm{C}$, and $2806 \mathrm{C}>\mathrm{G}$, is closely related to fasting plasma glucose and body mass index of normal people in Korea (Shin et al., 2004). Jia Weiping investigated the relationship between PPAR-delta and metabolic syndrome 
and found that gene polymorphism varies according to race (Hu et al., 2005). The $-87 \mathrm{~T} / \mathrm{C}$ mononucleotide polymorphism sites were selected in the present study to investigate the relationship between the mutation and glucose and fat metabolism of the said polymorphism, as well as the TNF $\alpha$ levels among Chinese people in Dalian. The frequencies of PPAR-delta and alleles of the patients included in the present study were more similar with those obtained by Jia Weiping (Hu et al., 2005) compared with those involving Korean subjects (Shin et al., 2004). However, the differences in the frequencies among the 3 studies were not significant.

The present study revealed significant differences in fasting plasma glucose and BMI between TT, TC, and CC genotypes in Group $\mathrm{T}_{2} \mathrm{DM}$, indicating that genetic polymorphism was related to diabetes among obese individuals. Moreover, triglyceride levels were significantly different between TC and CC genotypes, suggesting that triglyceride level was closely related with fat metabolism in patients with type 2 diabetes. In addition, the insulin resistance index and TNF $\alpha$ level were significantly different between TT and CC genotypes in Group $\mathrm{T}_{2} \mathrm{DM}$, suggesting that genetic polymorphism, as well as chronic inflammatory factors, were closely related to insulin resistance among patients with type 2 diabetes. The results obtained in the present study were similar to those of a recent study (Wang et al., 2003). Fasting plasma glucose was also significantly different between TT, CC, and TC genotypes. This result was obtained by calculating the sum of the square of differences in gene polymorphisms.

Studies involving animals have shown that fat deposition decreased and insulin sensitivity increased in obese mice that were fed a PPAR-delta agonist (Wang et al., 2003; Tanaka et al., 2003). Moreover, these studies have shown that the PPAR-delta gene has an obvious relationship with glucose and fat metabolism and insulin resistance, which is consistent with the results of the present study. Moreover, this study revealed the relationship between genetic polymorphisms and chronic inflammatory factors and provided a basis for future studies on the metabolism of PPAR-delta.

In summary, gene polymorphism of PPAR-delta, $-87 \mathrm{~T} / \mathrm{C}$, is closely related to obesity, plasma lipid abnormality, insulin resistance, and TNF $\alpha$ in individuals with type 2 diabetes in Dalian. PPAR-delta $-87 \mathrm{~T} / \mathrm{C}$ is also related to fasting plasma glucose and insulin resistance in individuals with normal fasting glucose. However, further studies are needed to determine the exact metabolism process of PPAR-delta $-87 \mathrm{~T} / \mathrm{C}$.

\section{REFERENCES}

Dressel U, Allen TL, Pippal JB, Rohde PR, et al. (2003). The peroxisome proliferator-activated receptor $\beta / \delta$ agonist, GW501516, regulates the expression of genes involved in lipid catabolism and energy uncoupling in skeletal muscle cells. Mol. Endocrinol. 17: 2477-2493.

Forman BM, Chen J and Evans RM (1997). Hypolipidemic drugs, polyunsaturated fatty acids, and eicosanoids are ligands for peroxisome proliferator-activated receptors $\alpha$ and $\delta$. Proc. Natl. Acad. Sci. U. S. A. 94: 4312-4317.

Holst D, Luquet S, Nogueira V, Kristiansen K, et al. (2003). Nutritional regulation and role of peroxisome proliferatoractivated receptor $\delta$ in fatty acid catabolism in skeletal muscle. Biochim. Biophys Acta 1633: 43-50.

Hu C, Jia WP, Fang QC and Zhang R (2005). Study for relationship between PPARD-87T $>$ C gene's polymorphism and metabolic syndrom. Chin. J. Endocr. Metab. 21: 380-383.

Kern PA, Ranganathan S, Li C, Wood L, et al. (2001). Adipose tissue tumor necrosis factor and interleukin-6 expression in human obesity and insulin resistance. Am. J. Physiol. Endocrinol. Metab. 280: E745-E751.

Lee CH, Chawla A, Urbiztondo N, Liao D, et al. (2003). Transcriptional repression of atherogenic inflammation: modulation by PPAR . Science 302: 453-457.

Leibowitz MD, Fievet C, Hennuyer N, Peinado-Onsurbe J, et al. (2000). Activation of PPAR $\delta$ alters lipid metabolism in db/db mice. FEBS Lett. 473: 333-336. 
Michalik L, Desvergne B, Tan NS, Basu-Modak S, et al. (2001). Impaired skin wound healing in peroxisome proliferatoractivated receptor (PPAR) $\alpha$ and PPAR $\beta$ mutant mice. J. Cell Biol. 154: 799-814.

Oliver WR, Jr., Shenk JL, Snaith MR, Russell CS, et al. (2001). A selective peroxisome proliferator-activated receptor $\delta$ agonist promotes reverse cholesterol transport. Proc. Natl. Acad. Sci. U. S. A. 98: 5306-5311.

Shin HD, Park BL, Kim LH, Jung HS, et al. (2004). Genetic polymorphisms in peroxisome proliferator-activated receptor $\delta$ associated with obesity. Diabetes 53: 847-851.

Skogsberg J, Kannisto K, Roshani L, Gagne E, et al. (2000). Characterization of the human peroxisome proliferator activated receptor $\delta$ gene and its expression. Int. J. Mol. Med. 6: 73-81.

Skogsberg J, Kannisto K, Cassel TN, Hamsten A, et al. (2003a). Evidence that peroxisome proliferator-activated receptor $\delta$ influences cholesterol metabolism in men. Arterioscler. Thromb. Vasc. Biol. 23: 637-643.

Skogsberg J, McMahon AD, Karpe F, Hamsten A, et al. (2003b). Peroxisome proliferator activated receptor $\delta$ genotype in relation to cardiovascular risk factors and risk of coronary heart disease in hypercholesterolaemic men. J. Intern. Med. 254: 597-604.

Tan NS, Michalik L, Noy N, Yasmin R, et al. (2001). Critical roles of PPAR $\beta / \delta$ in keratinocyte response to inflammation. Genes Dev. 15: 3263-3277.

Tanaka T, Yamamoto J, Iwasaki S, Asaba H, et al. (2003). Activation of peroxisome proliferator-activated receptor $\delta$ induces fatty acid $\beta$-oxidation in skeletal muscle and attenuates metabolic syndrome. Proc. Natl. Acad. Sci. U. S. A. 100: 15924-15929.

Wang YX, Lee CH, Tiep S, Yu RT, et al. (2003). Peroxisome-proliferator-activated receptor $\delta$ activates fat metabolism to prevent obesity. Cell 113: 159-170.

Yoshikawa T, Brkanac Z, Dupont BR, Xing GQ, et al. (1996). Assignment of the human nuclear hormone receptor, NUC1 (PPARD), to chromosome 6p21.1-p21.2. Genomics 35: 637-638.

Zinman B, Hanley AJ, Harris SB, Kwan J, et al. (1999). Circulating tumor necrosis factor- $\alpha$ concentrations in a native Canadian population with high rates of type 2 diabetes mellitus. J. Clin. Endocrinol. Metab. 84: 272-278. 